\title{
Isoelectric focusing, effect of reducing agents and inhibitors: partial characterization of proteases extracted from Bromelia karatas
}

\author{
María de Lourdes García-Magaña ${ }^{1} \cdot J^{\prime}$ ulián González-Borrayo ${ }^{1}$ • \\ Efigenia Montalvo-González ${ }^{1}$ Enrique Rudiño-Piñera ${ }^{2}$ • \\ Sonia G. Sáyago-Ayerdi ${ }^{1} \cdot$ Jesús Aarón Salazar-Leyva $^{3}$
}

Received: 17 March 2018/Accepted: 6 June 2018/Published online: 22 June 2018

(C) The Korean Society for Applied Biological Chemistry 2018

\begin{abstract}
The aim of this research is the partial characterization of proteases extracted from B. karatas; the isolation and purification of proteases from $B$. karatas fruits were achieved using precipitation, separation by size exclusion chromatography and anion-exchange chromatography; molecular mass (MM) was determined, and the effect of inhibitors, reducing agents and heat on enzyme activity was analyzed. These proteases were compared with proteases from Bromelia pinguin (B. pinguin) and evaluated under similar conditions. The isolation procedure was adequate; only a few protein bands are present in sodium dodecyl sulfate polyacrylamide gel electrophoresis. Furthermore, zymogram analysis showed protein bands with enzyme activity. Inhibitors, reducing agents and heat were unable to inactivate the proteases extracted from $B$. karatas and B. pinguin. The semi-purified extracts are a set of proteases with a MM of $66 \mathrm{kDa}$, but different isoelectric points (3.5-6.5 for B. karatas and 5-9 for B. pinguin), which are found in quaternary structures with proteolytic activity. When denatured, they segment into fragments of approximately 20 and $10 \mathrm{kDa}$. The
\end{abstract}

María de Lourdes García-Magaña

mgarciam@ittepic.edu.mx

1 Laboratorio Integral de investigación en Alimentos, División de Estudios de Posgrado, Instituto Tecnológico de Tepic, Av. Tecnológico 2595, CP 63175 Tepic, Nayarit, Mexico

2 Departamento de Medicina Molecular y Bio-procesos, Instituto de Biotecnología, Universidad Nacional Autónoma de México, Av. Universidad 2001, CP 62210 Cuernavaca, Morelos, Mexico

3 Maestría en Ciencias Aplicadas, Unidad Académica de Ingeniería en Biotecnología, Universidad Politécnica de Sinaloa (UPSIN), carretera Municipal Libre Mazatlán Higueras Km 3., 82199 Mazatlán, Sinaloa, Mexico data indicate that these plants could be used as sources of proteases since they present good proteolytic activity $\left(21.93 \mathrm{U}_{\mathrm{T}}\right.$ for proteases from B. karatas and $43.58 \mathrm{U}_{\mathrm{T}}$ for proteases from $B$. pinguin) and that $B$. Karatas has potential applications comparable to $B$. pinguin in the food and health industries.

Keywords Bromelia karatas fruits - Bromelia pinguin fruits · Inhibitors · Molecular mass · Purification · Zymography

\section{Introduction}

Proteases can be classified according to the characteristics of their active sites; this includes serine proteases, aspartic proteases, metalloproteinases and cysteine proteases [1]. In general, plant proteases have been used since ancient times. They are mainly applied in the food industry (brewing, baking, tenderizing and production of protein hydrolysates) and as a therapeutic alternative (anthelmintic, immune response modulators, wound healing and antitumor agents). Examples of these enzymes are bromelain and papain from pineapple (Ananas comosus) and papaya (Carica papaya), respectively. They act on a great diversity of proteins [2]. However, within the Bromeliaceae family there are other fruits such as Aguama or Guámara (Bromelia pinguin or $B$. pinguin) and Cocuixtle (Bromelia karatas or B. karatas) [3] that are considered rich in proteases and have hardly been studied. Nevertheless, their use has origins in preColumbian cultures dating back thousands of years [4].

Bromelia pinguin proteases have been mostly characterized. Toro-Goyco et al. [5] reported that the pinguinain protease obtained from B. pinguin fruit is a glycoprotein 
similar to papain that exhibits great resistance to heat denaturation with optimal activity at $65^{\circ} \mathrm{C}$ and $\mathrm{pH}$ of 8.2 [6]. It is also reported that pinguinain has a molecular mass (MM) of $20 \mathrm{kDa}$ [7]. In a recent study by Meza-Espinoza et al. [8], $K_{m}$ values for B. karatas and B. pinguin were determined; Moreno-Hernández et al. [9] demonstrated that crude enzymatic extracts from $B$. pinguin fruit showed high proteolytic properties; the proteases had adequate stability to oxidizing agents, reducing agents and organic solvents. On the other hand, Montes et al. [10] extracted proteases from B. plumieri (karatas) fruits and named a protein fraction karatasin with a MM of $24.86 \mathrm{kDa}$. However, there is currently no data on the B. karatas proteases. Moyano et al. [11] only performed physicochemical assays on $B$. karatas peel and pulp, finding a high protein content at an early (unripe) stage of maturity of the fruits that is likely related to the characteristic level of proteases of the Bromeliaceae family.

Different studies have reported associations between proteolytic enzymes and their health effects, indicating that plant proteases are helpful in treating digestive disorders, skin disorders, gastric ulcers, immunological modulation, anti-inflammatory and anticancer treatments [12-14]. They also prevent viral diseases, are diuretics and exfoliants [15] and have antibacterial activity $[8,16]$. Thus, the isolation and characterization of proteases from endemic plant sources are of great interest since they can be an alternative in the food and pharmacology industries. This is due to their stability under various physical and chemical conditions [17]. Therefore, the aim of this study was to isolate and purify proteases from $B$. karatas fruits and also compare them with proteases from $B$. pinguin fruits.

\section{Materials and methods}

\section{Plant material}

The mature fruits of Bromelia karatas (B. karatas) and Bromelia pinguin (B. pinguin) were acquired in a local market in Tepic, Nayarit, Mexico. The peel and seeds were discarded, and the pulp was freeze-dried (77522020, Labconco Corporation, Kansas city, MI, USA).

The general methodology of the isolation and partial characterization of the proteases can be seen in Fig. 1.

\section{Crude protease extraction}

Crude protease extraction (CPE) was carried out according to the methodology reported by López et al. (2000) [3]. Briefly, $10 \mathrm{~g}$ samples was taken and mixed with $250 \mathrm{~mL}$ of sodium phosphate buffer $(0.1 \mathrm{M}, \mathrm{pH} 6.0,5 \mathrm{mM}$ of EDTA and $5 \mathrm{mM}$ of L-cysteine at $4{ }^{\circ} \mathrm{C}$ ). The mixture was filtered and centrifuged at $6000 \mathrm{~g}$ for $30 \mathrm{~min}$ at $4{ }^{\circ} \mathrm{C}$ (Hermle, Z32HK, Wehingen, Germany). The supernatant was used as the CPE.

\section{Precipitation of proteases with ammonium sulfate}

Ammonium sulfate was added (20 and 30\% w/v, respectively) to the CPE of B. karatas and B. pinguin [17]. The obtained precipitate was dialyzed through a cellulose membrane (D0530-30.8 m avg, Flat width $32 \mathrm{~mm}$, $12,400 \mathrm{Da}$, Sigma-Aldrich) for $45 \mathrm{~h}$ at $4{ }^{\circ} \mathrm{C}$ with constant recirculation of deionized water. Electric conductivity was monitored during the whole process (Conductivity Meters HANNA Instruments, HI 4521 TX, USA). The desalted precipitates were named desalted proteases.

\section{Concentration of proteases by ultrafiltration}

The desalted proteases were then diafiltrated and concentrated in centrifuge ultrafiltration tubes with a MM cutoff of $10 \mathrm{kDa}$ (Amicon Ultra-15 Centrifugal Filters Merck Millipore, Darmstadt, Germany); centrifugation was performed at $4000 \mathrm{~g}$ for $40-60 \mathrm{~min}$ until reaching a volume of $0.5 \mathrm{~mL}$, equivalent to a volumetric reduction factor (VRF) of 30 . These concentrated proteases were analyzed in different ways:

(a) The samples were directly analyzed by zymography (proteolytic activity), electrophoresis and isoelectric focusing (IEF).

(b) The samples were mixed with a protease inhibitor kit (cOmplete $^{\mathrm{TM}}$ Protease Inhibitor Cocktail Tablets, Roche Diagnostics GmbH, Mannheim, Germany) and treated by size exclusion chromatography (SEC). The samples were then analyzed by electrophoresis and zymography.

(c) The samples were submitted to reducing and denaturing conditions, with dithiothreitol (DTT) $50 \mathrm{mM}$ or DTT with/without heat at $98{ }^{\circ} \mathrm{C}$ as reducing agents and analyzed by electrophoresis and zymography.

(d) The samples were purified by SEC and then by anion-exchange chromatography and subsequently analyzed by Native-PAGE, zymography and IEF.

\section{Proteolytic activity}

The proteolytic activity in the protease extracts was measured to verify that activity remained intact after extraction and prior to prepurification. The method described by Natalucci et al. [18] was followed; the substrate was modified using ovalbumin. Briefly, $1.1 \mathrm{~mL}$ of ovalbumin solution $(1 \mathrm{~g} / 100 \mathrm{~mL})$ was mixed with phosphate buffer 


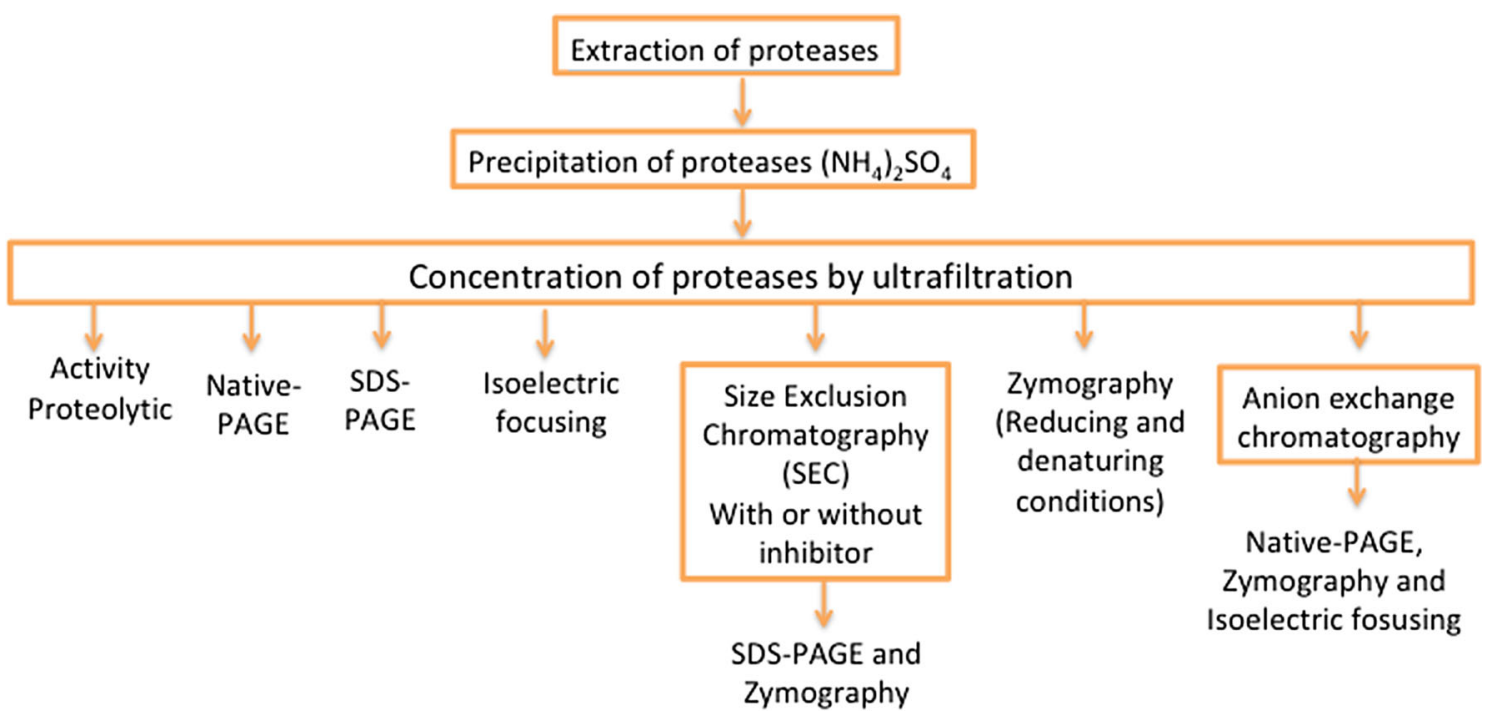

Fig. 1 General diagram of study of proteases prepurified from B. karatas and B. pinguin

(pH $6.0,12.5 \mathrm{mM}$ of L-cysteine) and $0.1 \mathrm{~mL}$ of crude protease extract at $37{ }^{\circ} \mathrm{C}$. The reaction was stopped adding $1.8 \mathrm{~mL}$ of trichloroacetic acid $(50 \mathrm{~g} / \mathrm{L})$. Then, the solution was centrifuged $(18,500 \mathrm{~g} ; 10 \mathrm{~min}$; Hettich, Mikro 200R, Tuttlingen, Germany) and the absorbance of the supernatant was measured at $280 \mathrm{~nm}$ (JENWAY, 6705, Bibby Scientific Limited, OSA, UK). A calibration curve with tyrosine was used to determine the specific activity that was defined as the milligrams of tyrosine produced per milligram of protein per minute ( $\mathrm{mg} \mathrm{Tr} / \mathrm{mg}$ prot $\mathrm{min}$ ) at $37^{\circ} \mathrm{C}$. Protein concentration was determined by the Bradford method [19].

\section{Native-polyacrylamide gel electrophoresis (Native- PAGE)}

The Native-PAGE was carried out on automatic equipment (PhastSystem Separation, GE Healthcare Bio-Sciences AB, Uppsala, Sweden) with preformed gels (GE Healthcare, PhastGel 20\% Homogeneous, GE Healthcare Bio-Sciences $\mathrm{AB})$. The ultrafiltration-concentrated proteases of both fruits (B. karatas and B. pinguin) were loaded onto the gel without pretreatment, and the separation was subsequently developed according to the Separation Technique File No. 120 of the Phast System Manual (1995). A MM standard (26619 PageRuler Plus Prestained Protein Ladder, 10-250 kDa Thermo Scientific) was used.

\section{Sodium dodecyl sulfate polyacrylamide gel electrophoresis (SDS-PAGE)}

The concentrated proteases or protein fractions were performed in a 15\% SDS-PAGE gel [20]. After electrophoresis, the stained gels were scanned and analyzed using Image Lab Software (Bio-Rad Laboratories). A MM standard of $10-250 \mathrm{kDa}$ was used.

\section{Isoelectric focusing (IEF)}

IEF was performed on automatic equipment (Pharmacia, PhastSystem Separation, GE Healthcare Bio-Sciences AB) with preformed gels (GE Healthcare, PhastGel IEF, GE Healthcare Bio-Sciences AB). The concentrated proteases or protein fractions were loaded onto the IEF gel. An isoelectric point (IP) standard (GE Healthcare, PhastGel IEF 3-9 Broad pI, GE Healthcare Bio-Sciences AB) was employed.

\section{Zymogram (reducing and denaturing conditions)}

The concentrated proteases were subjected to zymography following the procedure proposed by Le and Katunuma [21] in PAGE without reducing agents for each analysis, using gelatin $(1 \mathrm{mg} / \mathrm{mL})$ as substrate for the proteases. The PAGE was incubated in Tris-HCl buffer ( $\mathrm{pH} \mathrm{8.0).} \mathrm{The}$ stained gels were scanned and analyzed using Image Lab Software (Bio-Rad Laboratories). An MW standard of 10-250 kDa was used.

\section{Separation by size exclusion chromatography (SEC)}

Samples concentrated by ultrafiltration (MCU) were fractionated using a Superdex-75 chromatography column mounted on a FPLC system (GE Healthcare, ÄKTA Pure 25 L, GE Healthcare Bio-Sciences Corp.). Sodium Phosphate buffer (0.1 M, pH 5.5) containing $10 \mathrm{mM} \mathrm{NaCl}$ was employed for the mobile phase. Each fraction $(1 \mathrm{~mL})$ was collected in a GE Fraction Collector F9-R (GE Healthcare, 
Fraction Collector F9-R, GE Healthcare Bio-Sciences Corp.), and the absorbance was monitored at $280 \mathrm{~nm}$. The chromatogram was analyzed with UNICORN software. The fractions were analyzed by SDS-PAGE and zymography. Also, a concentrated sample was analyzed under this method by ultrafiltration of $B$. Karatas that remained in conventional freezing in order to determine whether the low temperatures would have an effect.

\section{Separation by size exclusion chromatography (SEC) with protease inhibitors}

Samples concentrated by ultrafiltration were mixed with a protease inhibitor kit (cOmplete $^{\mathrm{TM}}$ Protease Inhibitor Cocktail Tablets, Roche Diagnostics GmbH, Mannheim, Germany). After the reaction, the samples were concentrated again using the same centrifuge ultrafiltration tubes (Amicon Ultra-15 Centrifugal Filters). The samples were fractionated under the conditions mentioned for SEC. The chromatogram was analyzed with UNICORN software, and the fractions were performed by SDS-PAGE and zymography.

\section{Separation by anion-exchange chromatography}

The samples concentrated by ultrafiltration were also separated with anion-exchange chromatography in a column (Pharmacia, mono Q, GE Healthcare Bio-Sciences Corp.) mounted on an FPLC system (GE Healthcare, ÄKTA Pure 25 L, GE Healthcare Bio-Sciences Corp.). The column was equilibrated with Bis-Tris propane buffer ( $\mathrm{pH}$ 9.5). The column was washed with the same buffer afterward. The proteins were eluted with $400 \mathrm{~mL}$ of a linear sodium chloride gradient $(65-190 \mathrm{mM}$ to elute proteases from $B$. karatas and $80-190 \mathrm{mM}$ to elute proteases from B. pinguin) in the starting buffer. Each fraction $(8 \mathrm{~mL})$ was collected in a Fraction Collector (GE Healthcare, Fraction Collector F9-R, GE Healthcare Bio-Sciences Corp.), and the absorbance was measured at $280 \mathrm{~nm}$. The chromatogram and zymogram were analyzed with UNICORN software. The fractions were analyzed by zymography and IEF.

\section{Results}

\section{Proteolytic activity}

The proteolytic activity of the concentrated proteases was $21.93 \mathrm{U}_{\mathrm{T}}$ for proteases from B. karatas and $43.58 \mathrm{U}_{\mathrm{T}}$ for proteases from the $B$. pinguin. This means that the extraction process did not affect the proteolytic activity, although it was clear that proteases from $B$. pinguin had higher enzymatic activity than proteases from $B$. karatas.

\section{Native-PAGE and isoelectric focusing of concentrated proteases}

The Native-PAGE shows (Fig. 2A) bands with MMs of approximately $55-70 \mathrm{kDa}$ according to the MM standard used. On the other hand, IEF (Fig. 2B) shows the presence of several bands corresponding to proteins with several different isoelectric points (IPs). The proteases from $B$. karatas had IPs from 3.5 to 6.5 , while the proteases from $B$. pinguin $\mathrm{pIs}$ ranged from 3.9 to 8.6 . The results indicate that there are different kinds of proteases depending on the plant species. Due to the lack of studies on this topic, the results of this study regarding B. karatas are important.

\section{SDS-PAGE and zymography of purified proteases obtained by size exclusion chromatography (SEC) with and without inhibitors}

The use of inhibitors was for the purpose of ruling out the possibility that the bands of low MM were the product of hydrolysis after the exclusion chromatography. The proteases treated with and without inhibitor were subjected to SEC to be analyzed. In Fig. 3A one can see that the proteases with and without inhibitors from $B$. karatas or $B$. pinguin had MMs from approximately 35 to $70 \mathrm{kDa}$; this was also observed by Native-PAGE (Fig. 2A). Furthermore, in the zymogram (Fig. 3B) it is observed that in spite of adding inhibitors, the proteases had maintained their proteolytic activity. The greatest enzymatic activity is seen in the regions where the MM of proteases was registered, which was higher when proteases from $B$. pinguin were used when compared to proteases from B. karatas (Fig. 3B, Lines 4 and 5).

\section{SDS-PAGE and zymogram of concentrated proteases with denaturing and reducing conditions}

For practical purposes, it is of interest to analyze the effect of denaturing and reducing conditions in concentrated proteases, as well as measure their stability. In Fig. 4 it is observed that the MMs of proteases from both plant species without denaturing and reducing treatments (Fig. 4A, Lines 2 and 3) remained unchanged. However, there was a partial denaturation when the proteases were treated with DTT (Fig. 4A, Lines 4 and 5) observing bands with MMs between 60 and $10 \mathrm{kDa}$; while there was a greater denaturation when the proteases were treated with DTT and heat, there were bands with MMs approximately from 20 to $10 \mathrm{kDa}$ (Fig. 4A, Lines 6 and 7). The highest proteolytic activity was observed in the non-treated proteases (Fig. 4B, 
Fig. 2 (A) Native-PAGE of concentrated proteases. Line 1) Bk, B. karatas; Line 2) Bp, B. pinguin; Line 3) MW, molecular weight standard. (B) Isoelectric focusing of concentrated proteases. Line 1) $\mathrm{Bk}$, B. karatas; 2) Bp, B. pinguin; 3 ) pIs, isoelectric point standard
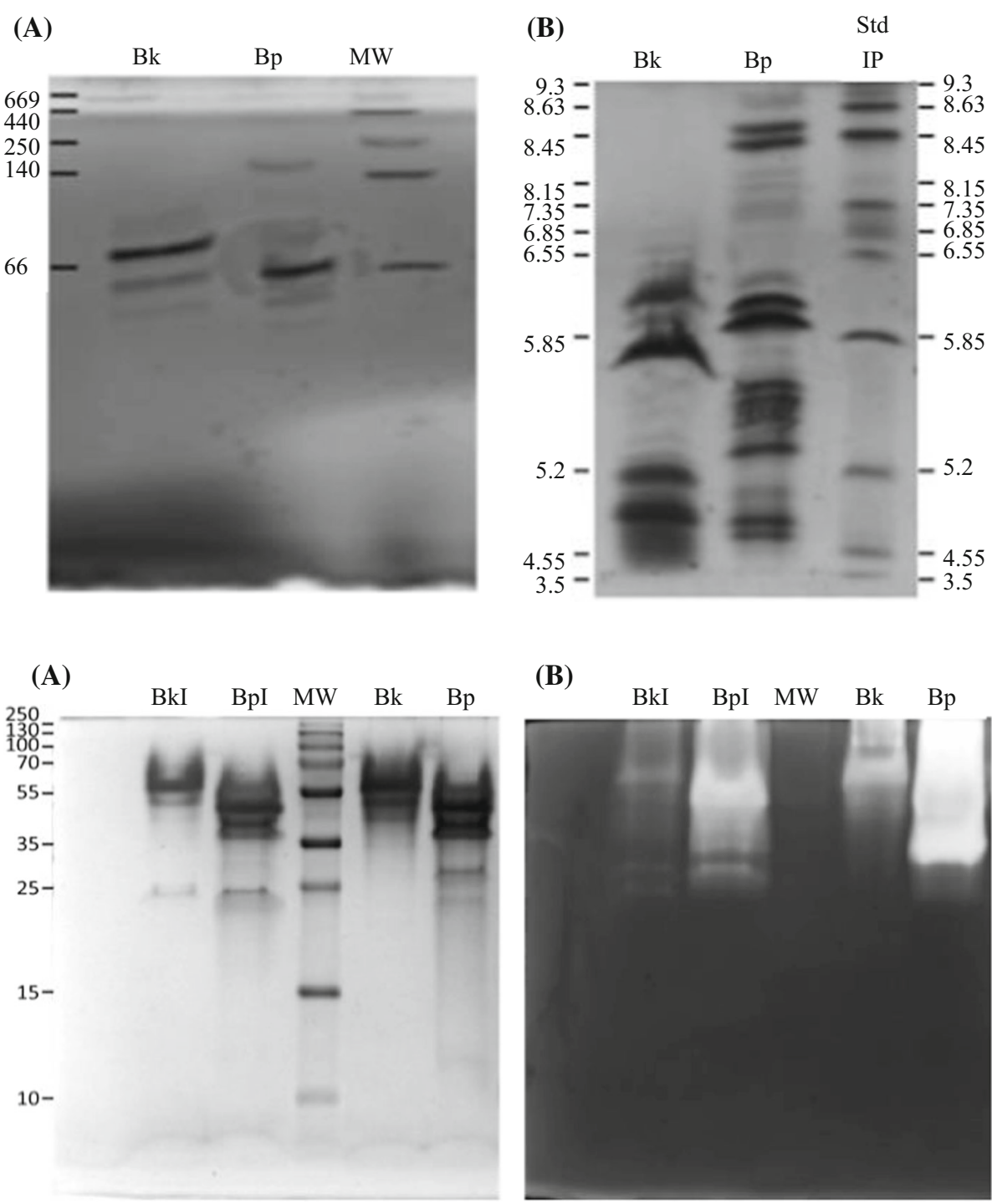

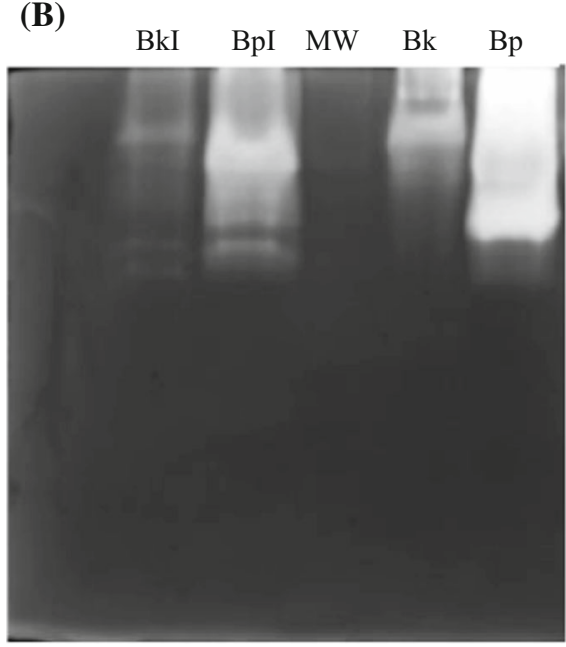

(B)

\author{
zymography $(\mathbf{B})$ of concentrated \\ proteases with and without \\ inhibitors. Line 1: Bk I, \\ proteases from $B$. karatas with \\ inhibitors; Line 2: Bp I, \\ proteases from $B$. pinguin with \\ inhibitors; Line 3: MW, \\ molecular weight standard; Line \\ 4: Bk, proteases from $B$. karatas \\ without inhibitors; Line 5: Bp, \\ proteases from $B$. pinguin \\ without inhibitors
}

Fig. 3 SDS-PAGE (A) and
Lines 2 and 3); while the proteolytic activity decreased in proteases treated with DTT (Fig. 4B, Lines 4 and 5) confirming a partial denaturalization. However, the proteases treated with DTT and heat did not present proteolytic activity (Fig. 4B, Lines 6 and 7), demonstrating that the evaluated proteins are proteases and were completely denaturalized.

\section{Native-PAGE, zymography and isoelectric focusing of purified proteases obtained by anion-exchange chromatography}

Another method of purification was anion-exchange chromatography (AEC), which was done for the purpose of comparison with the SEC method. In the separation with AEC, it was observed that both $B$ karatas and $B$ pinguin proteases had relatively high MMs (Fig. 5A, C) coinciding with the results obtained in SEC. White bands are observed in the zymogram (Fig. 5B, D), which confirmed that the activity of the obtained proteases by this purification method was also preserved. In the same way, their activity coincided with the height of bands registered in the electrophoresis (Fig. 5).

With the goal of finding similarities between proteases, these were subjected to IEF. In fractions 7, 14, 17, 18, 21, 24 and 27 (Fig. 6A), proteases with different IPs were collected from B. karatas (fraction 7, 3.75-6.0; fraction 14, 3.75-5.5; fraction 17 and 18, 3.5-4.55, fraction 21, 3.75; fraction 24, 3.3-5.85). In some fractions, the IP's were repeated and presented proteolytic activity as is shown in Fig. 5B. In the fractions 7, 12, 30 and 36 of $B$. pinguin extract (Fig. 6B), proteases of different IP's were also collected (fraction 7, 8.2-8.65; fraction 12, 5.85-6; fraction 30, 5.9-6; fraction 36, 4.55-5.3). Only fractions 12 and 30 coincide with a band corresponding to a IP of 6 . In 


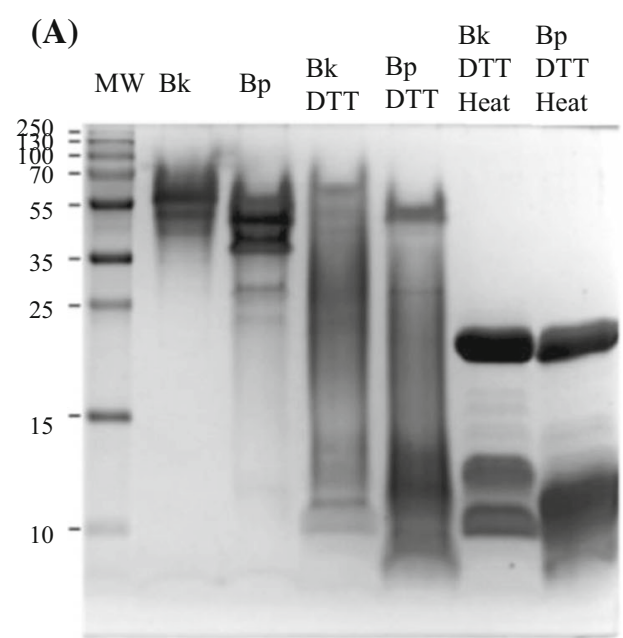

Fig. 4 SDS-PAGE (A) and zymography (B) of concentrated proteases without and with denaturing and reducing conditions. Line 1: MW, molecular weight standard; Line 2: $\mathrm{Bk}$, proteases from $B$. karatas; Line 3: Bp, proteases from B. pinguin; Line 4: Bk DTT,

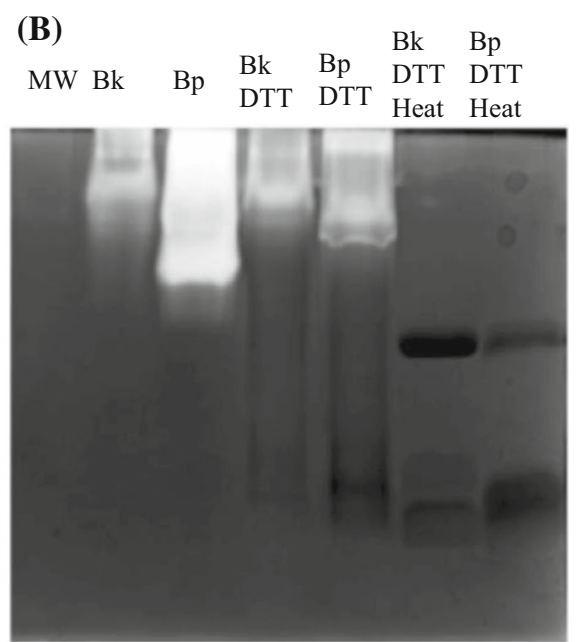

proteases from B. karatas with dithiothreitol; Line 5: Bp DTT, proteases from $B$. pinguin with dithiothreitol; Line 6: Bk DTT Heat, proteases from B. karatas with dithiothreitol + heat; Line 7: Bp DTT Heat, proteases from $B$. pinguin with dithiothreitol + heat

(A)

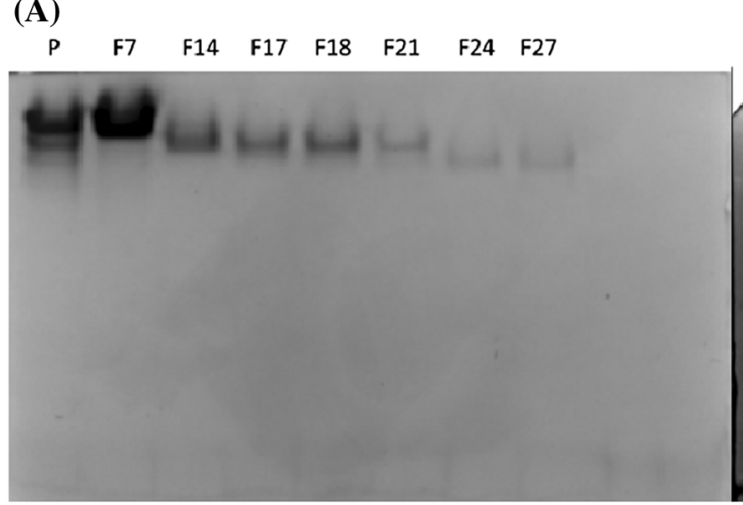

(B)

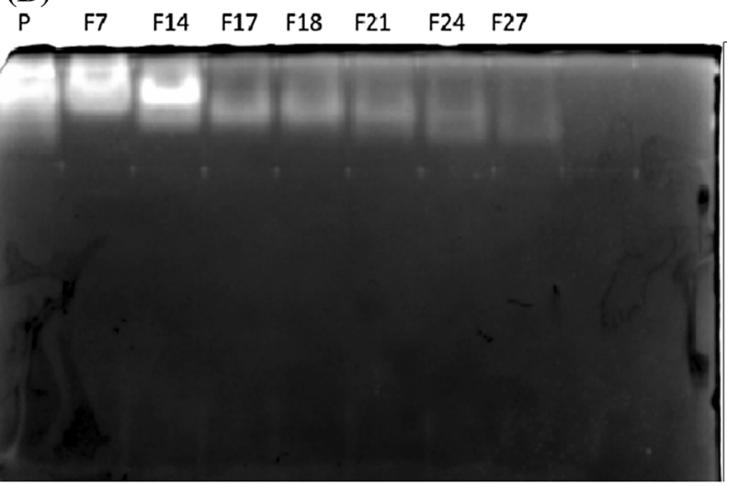

(C)
F2 F3
F23 F26
F30 F36

F7 F1

F13

(D)

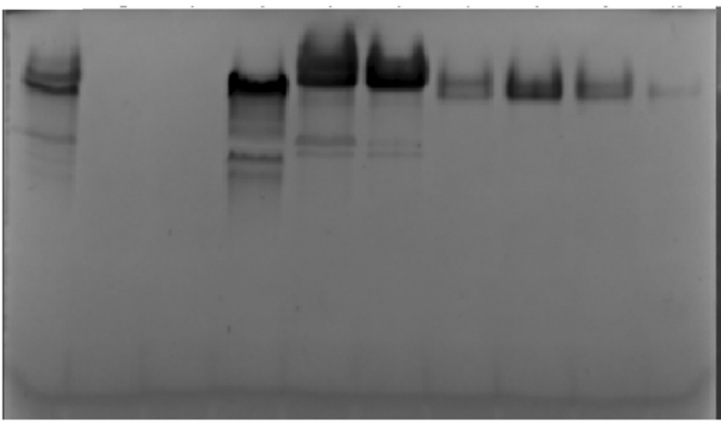

$\begin{array}{lllllllll}\text { F2 } & \text { F3 } & \text { F7 } & \text { F12 } & \text { F13 } & \text { F23 } & \text { F26 } & \text { F30 } & \text { F36 }\end{array}$

Fig. 5 (A) Native-PAGE of the fractions obtained from the anionexchange chromatography of the diafiltered extracts of B. karatas and $F$ fraction; (B) zymography of the fractions obtained from the anionexchange chromatography of the diafiltered extracts of B. karatas and $F$ fraction; (C) Native-PAGE of the fractions obtained from the anion-exchange chromatography of the diafiltered extracts of $B$. pinguin and $F$ fraction and (D) zymography of the fractions obtained from the anion-exchange chromatography of the diafiltered extracts of $B$. pinguin and $F$ fraction 
(A)

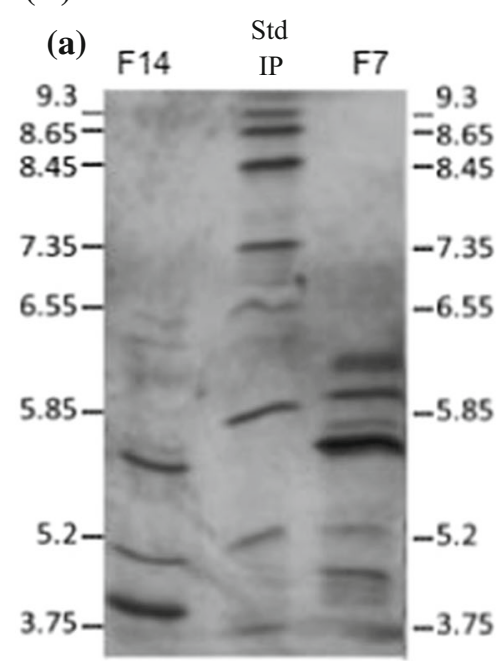

(B)

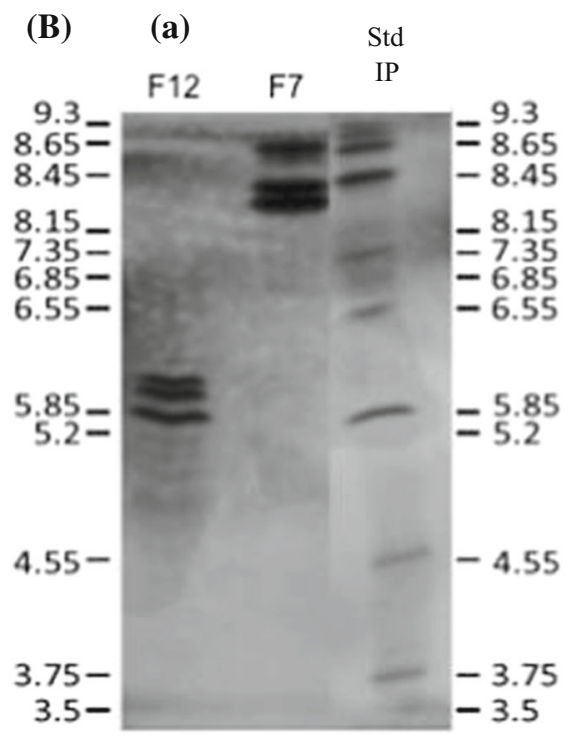

Fig. 6 (A) Isoelectric focusing of the fractions obtained from the anion-exchange chromatography of the diafiltered extracts of $B$. Karatas and $F$ fraction; (B) isoelectric focusing of the fractions

addition, it can also be seen that some fractions are composed of more than one band of protein.

These results are interesting, because they show the existence of different proteases that could have different cutoff points in a protein; this is important since the proteases from $B$ karatas have not been fully studied.

\section{Discussion}

The reported proteolytic activity of proteases from $B$. pinguin and $B$. karatas fruits is variable; for example, for proteases from $B$. pinguin extract, the reported values were $11 \mathrm{U}_{\text {cas }} / \mathrm{mL}$ [6], $2.31 \mathrm{U}_{\text {cas }} / \mathrm{mg}$ [8], $0.98 \mathrm{U}_{\text {cas }} / \mathrm{mL}$ [16], 3.2 $\mathrm{U} / \mathrm{mg}$ [17], while for proteases from B. karatas extract, the
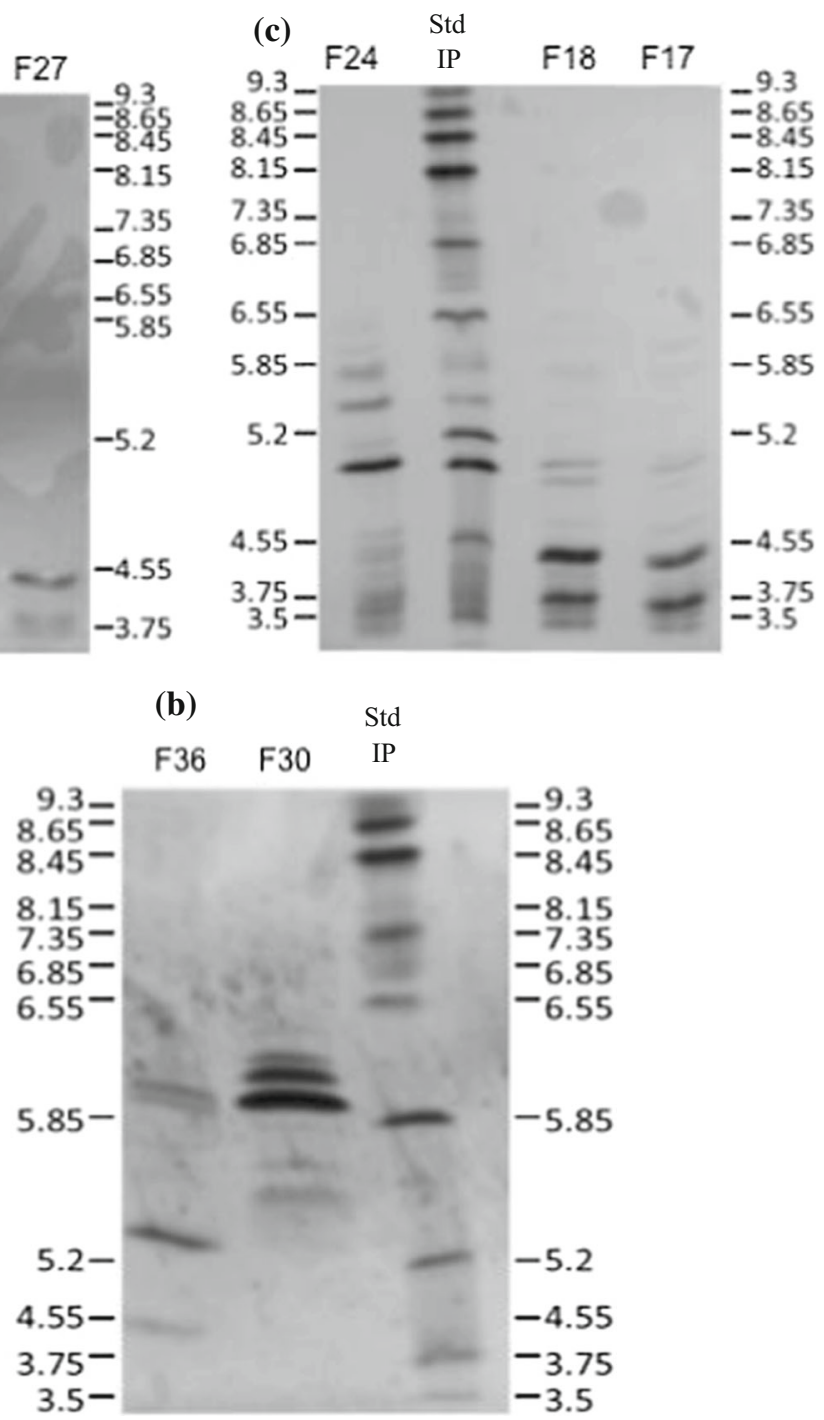

obtained starting from the chromatography of anion exchange of the fruit of $B$. pinguin and $F$ fraction

reported value was $1.2 \mathrm{azocol} / \mathrm{mg} \mathrm{min} / \mathrm{mL}$ [10]. In this work, the proteolytic activity of the concentrated proteases was $21.93 \mathrm{U}_{\mathrm{T}}$ for proteases from B. karatas and $43.58 \mathrm{U}_{\mathrm{T}}$ for proteases from $B$. pinguin. The proteolytic activity of bromelain was used as control to analyze the result, which was $27.83 \mathrm{U}_{\mathrm{T}}$. These findings highlight the high activity of $B$. pinguin proteases. The proteolytic activity presented by $B$. karatas, although inferior, is comparable to the control activity and can be considered a promising result for this little studied fruit. On the other hand, the presence of proteins with proteolytic activity was observed in both fruits, verifying that the techniques for obtaining the enzymes were suitable (Table 1).

The MM of the proteins under non-denaturing conditions was corroborated in the Native-PAGE of the samples 
Table 1 Protein content, activity units and specific activity of purified proteases from Bromeli Karatas and Bromelia Pinguin fruits

\begin{tabular}{llllcl}
\hline Vegetal species & Step & Protein $(\mathrm{mg} / \mathrm{mL})$ & Activity units $(U)$ & Specific activity $(U / \mathrm{mg}$ protein) & Purification $(n$-fold) \\
\hline B. Karatas & Crude extract & $0.55 \pm 0.016$ & $3.62 \pm 0.38$ & $6.58 \pm 0.70$ & 1 \\
& I (Precipitation) & $0.49 \pm 0.01$ & $2.49 \pm 0.34$ & $5.08 \pm 0.70$ & 0.77 \\
& II (Ultrafiltration) & $0.24 \pm 0.01$ & $5.26 \pm 0.003$ & $21.93 \pm 0.35$ & 3.33 \\
B. pinguin & Crude extract & $0.73 \pm 0.007$ & $9.54 \pm 0.23$ & $17.35 \pm 0.43$ & 1 \\
& I (Precipitation) & $0.12 \pm 0.004$ & $5.35 \pm 0.27$ & $41.27 \pm 1.06$ & 2.37 \\
& II (Ultrafiltration) & $0.12 \pm 0.003$ & $5.40 \pm 0.001$ & $43.58 \pm 0.40$ & 2.51 \\
\hline
\end{tabular}

Means \pm standard deviations $(n \geq 3)$ with different letters within columns are statistically different $(\alpha=0.05)$

$U$ : activity unit (mM/min)

concentrated by ultrafiltration (Fig. 2A), where a MM from 55 to $70 \mathrm{kDa}$ was observed.

IEF (Fig. 2B) shows that the samples concentrated by ultrafiltration of both fruits are formed by a complex mixture of proteins with different isoelectric points. The difference between the isoelectric points leads us to think that more information about the proteases could be found through ion exchange chromatography. The extract of the $B$. pinguin fruit presented IPs similar to those reported by Payrol et al. [6] for extracts of B. pinguin in fruits grown in Cuba. The IPs were between 3.5 and 6.5, for B. karatas; data were previously unknown.

When comparing the SDS-PAGE results of the fractions obtained from the SEC with inhibitor (Fig. 3A, Lines 2 and 3 ), with the SDS-PAGE results of the fractions of the SEC (FPLC) without protease inhibitor (Fig. 3A, Lines 5 and 6), no difference was observed in the electrophoretic pattern, thus ruling out the possibility that the low MM bands were the product of hydrolysis that followed after molecular exclusion chromatography.

The zymogram (Fig. 3B) of the samples concentrated by ultrafiltration with and without inhibitor showed partial inhibition of the enzymatic extracts of both fruits. In addition, the $20 \mathrm{kDa}$ and $10 \mathrm{kDa}$ bands previously observed in SDS-PAGE could be subunits of a quaternary enzyme structure; this was reaffirmed when the zymograms used to determine the effects of reducing and denaturing agents were analyzed. The concentrates treated with heat and DTT (Fig. 4) showed low MM bands; this could be the product of the separation of quaternary structures into protein subunits.

Observing proteolytic activity only in the high MM bands (Fig. 4), it can be proposed that the proteolytic enzymes must consist of a quaternary structure (approximately $55 \mathrm{kDa}$ ) to present the proteolytic activity mentioned above. The MM of the proteins under nondenaturing conditions was about 55-70 kDa (Fig. 2A); similar results were reported by Singh et al. [22], who performed electrophoresis under reducing and non- reducing conditions of a serine protease extracted from Morus indica cv. K2. They found it had a MM of approximately $120 \mathrm{kDa}$ under non-denaturing and $66 \mathrm{kDa}$ under denaturing conditions as confirmed by MALDI-TOF MS/ES ${ }^{+}$, a dimer with subunits of 67.195 and $67.302 \mathrm{kDa}$. Additionally, they discovered through zymography that the serine protease presents activity only when it is in its dimer conformation. When comparing the results obtained in the present work with that of Singh et al. [22], it is confirmed that the proteases present in the analyzed diafiltrates extracts have the quaternary structures necessary for proteolytic activity.

The decrease, but not the absence of proteolytic activity by the effect of DTT, is interesting (Fig. 4B); this behavior may be due to the fact that DTT is a reducing agent of sulfhydryl groups, which is used to eliminate the disulfide bonds between one or more polypeptide chains. However, it is also known that at low concentrations, DTT protects the proteolytic activity of extracts of $B$. pinguin [23], because it favors the formation of sulfhydryl group (-SH), allowing the active site of the enzyme to be active. It is important to note that similar effects of DTT on B. karatas were observed in this study; one could consider that its proteases are also cysteine proteases.

The effect observed when combining DTT and heat could be due to the fact that proteins with quaternary structures are separated into their respective subunits after the interactions that stabilize such structures-hydrogen bonds and disulfide bonds-disappear [24], resulting in the observed loss of activity.

Zymography (Fig. 5B, D) and IEF (Fig. 6) showed that for $B$. pinguin, some fractions are composed of more than one protein band, so that the activity observed in the zymogram (Fig. 6) cannot be the product of a single enzyme or a set of these with relatively close IPs, while for B. karatas fractions 7, 14, 17 and 18, only the IP bands are repeated in fractions 17 and 18 . This leads to the assumption that extracts of B karatas are composed of at least three distinct proteases. This is important, since 
several proteases can cut a protein at different sites and translate into generation of lower MM peptides [25].

The proteolytic activity of extracts of $B$. karatas, although lower than those of $B$. pinguin, is comparable with bromelain; its $\mathrm{MM}$ is similar to the extracts of $\mathrm{B}$ pinguin. It also presents similar proteolytic stability to $B$. pinguin before inhibitors and DTT, so it could be thought that it is also a cysteine protease. It can be adequately purified by SEC or AEC and have IPs of 3.5-6.5. Unlike $B$. pinguin, it could be considered that the extracts in $B$. karatas are composed of at least three distinct proteases, which would allow it to have a greater number of protein cut sites and generate smaller peptides, an interesting feature in a protease. This shows the importance of further study on the extracts of this fruit.

\section{Compliance with ethical standards}

Conflict of interest The authors declare that they have no conflict of interest.

Human or animals rights This article does not contain any studies with human participants or animals performed by any of the authors.

\section{References}

1. Palma JM, Sandalio LM, Corpas F, Romero-Puertas MC, McCarthy I, Del Río L (2002) Plant proteases, protein degradation, and oxidative stress: role of peroxisomes. Plant Physiol Biochem 40:521-530

2. Feijoo-Siota L, Villa TG (2011) Native and biotechnologically engineered plant proteases with industrial applications. Food Bioprocess Technol 4:1066-1088

3. López LMI, Sequeiros C, Natalucci CL, Brullo A, Maras B, Barra D, Caffini NO (2000) Purification and characterization of macrodontain I, a cysteine peptidase from unripe fruits of Pseudananas macrodontes (Morr.) Harms (Bromeliaceae). Protein Expr Purif 18:133-140

4. Bennett B (2000) Ethnobotany of Bromeliaceae. In: En Benzing DH (ed) Bromeliaceae, profile of an adaptive radiation. Cambridge University Press, Cambridge, pp 587-608

5. Toro-Goyco E, Maretzki A, Matos ML (1968) Isolation, purification, and partial characterization of Pinguinain, the proteolytic enzyme from Bromelia pinguin L. Arch Biochem Biophys 126(1):91-104

6. Payrol AJ, Obregón WD, Natalucci CL, Caffini NO (2005) Reinvestigation of the proteolytically active components of Bromelia pinguin fruit. Fitoterapia 76(6):540-548

7. Pío León JF, López AG, Paredes LO, Uribe Beltrán M, Díaz Camacho SP, Delgado Vargas F (2009) Physicochemical, nutritional and antibacterial characteristics of the fruit of Bromelia pinguin L. Plant Foods Hum Nutr 64:181-187

8. Meza-Espinoza L, Vivar-Vera ML, García-Magaña ML, SáyagoAyerdi SG, Chacón-López AM, Becerra-Verdín EM, MontalvoGonzález E (2017) Enzyme activity and partial characterization of proteases obtained from Bromelia karatas fruit and compared with Bromelia pinguin proteases. Food Sci Biotechnol. https:// doi.org/10.1007/s10068-017-0244-6
9. Moreno-Hernández JM, Hernández-Mancillas XD, Coss NEL, Mazorra-Manzano MA, Osuna-Ruiz I, Rodríguez-Tirado VA, Salazar-Leyva JA (2017) Partial characterization of the proteolytic properties of an enzymatic extract from "aguama" Bromelia pinguin L. fruit grown in Mexico. Appl Biochem Biotech 182:181-196

10. Montes C, Amador M, Cuevas D, Cordoba F (1990) Subunit structure of karatasin, the proteinase isolated from Bromelia plumieri (karatas). Agric Biol Chem 54(1):17-24

11. Moyano DD, Osorio RM, Murillo PE, Murillo AW, Solanilla DJ, Méndez AJ, Aristazabal SJ (2012) Evaluación de parámetros bromatológicos, fitocoquímicos y funcionalidad antioxidante de frutos de Bromelia karatas (Bromeliaceae). Vitae 19(1):S439_ S441

12. Wen S, Huang THW, Li GQ, Yamahara J, Roufogalis BD, Li Y (2006) Bromelain improves decrease in defecation in postoperative rats: modulation of colonic gene expression of inducible nitric oxide synthase. Life Sci 78(9):995-1002

13. Salas CE, Gómes MTR, Hernández M, Lópes MTP (2008) Plant cysteine proteinases: evaluation of the pharmacological activity. Phytochem 69:2263-2269

14. Pavan R, Jain S, Shraddha Kumar A (2012) Properties and therapeutic application of bromelain: a review. Biotechnol Res Int. https://doi.org/10.1155/2012/976203

15. Maurer HR, Eckert K, Grabowska E, Eschmann K (2000) Use of bromelain proteases for inhibiting blood coagulation. Patent WO PCT/EP 98/04406

16. Ruíz-Ruíz JC, Ramón-Sierra J, Arias-Argaes C, Magaña-Ortíz D, Ortiz-Vázquez E (2016) Antibacterial activity of proteins extracted from the pulp of wild edible fruit of Bromelia pinguin L. Int J Food Prop 20:220-230

17. Moreno-Hernández JM, Hernández-Mancillas XD, Coss Navarrete EL, Bañuelos-Pérez MJ, Salazar-Leyva JA, Osuna-Ruíz I, Rodríguez-Tirado VA, Mazorra-Manzanzo MA (2017) Partial characterization of milk-clotting and caseinolytic activities of "aguama" fruit (Bromelia pinguin L.) proteases. Biotecnia XIX(2):19-24

18. Natalucci CL, Brullo A, López MI, Hilal RM, Caffini NO (1996) Macrodontain, a new protease isolated from fruits of Pseudananas macrodontes (Morr.) Harms (Bromeliaceae). J Food Biochem 19:443-454

19. Bradford MM (1976) A rapid and sensitive method for the quantitation microgram quantities of protein utilizing the principle of protein-dye binding. Anal Biochem 72:248-254

20. Laemmli UK (1970) Cleavage of structural proteins during the assembly of the head of bacteriophage T4. Nature 227(5259):680-685

21. Le Q, Katunuma N (2004) Detection of protease inhibitors by a reverse zymography method, performed in a tris(hydroxymethyl)aminomethane-tricine buffer system. Anal Biochem 324(2):237-240

22. Singh VK, Patel AK, Moir AJ, Jagannadham MV (2008) Indicain, a dimeric serine protease from Morus indica cv. K2. Phytochem 69:2110-2211

23. Payrol JA, Obregón WD, Trejo SA, Caffini NO (2008) Purification and characterization of four new cysteine endopeptidases from fruits of Bromelia pinguin L. grown in Cuba. Protein $\mathrm{J}$ 27(2):88-96

24. Jones S, Thornton JM (1995) Protein-protein interactions: a review of protein dimer structures. Prog Biophys Mol Biol 63(1):31-65

25. Bamdad F, Wu J, Chen L (2011) Effects of enzymatic hydrolysis on molecular structure and antioxidant activity of barley hordein. J Cereal Sci 54(1):20-28 